\title{
Dorados marmolados en policromías de retablos rococós. Una nueva técnica'
}

\author{
Bárbara Hasbach Lugo,Teresa Gómez Espinosa
}

Resúmen: En los retablos españoles dieciochescos se despliega un variado repertorio de acabados en el dorado jugando con efectos mates y brillantes, cincelados y bronceados. Aquí se presenta una técnica hasta ahora desconocida que combina el bronceado con un efecto marmolado.

La primera vez que encontramos esta técnica fue en Madrid, en el retablo mayor de Meco; posteriormente pudimos localizarla en Ávila, Nájera, Coria y Albarracín. En dos casos, Meco y Ávila, se ha documentado el nombre de Próspero Mortola, dorador real. También se detectaron fuera de España, en México, en la iglesia de Santa Prisca, en Taxco.

Por tanto, nos hallamos ante una técnica de policromía barroca no estudiada hasta la fecha, que podemos situar entre fines del primer tercio y el tercio central de la decimoctava centuria y que se asocia con el estilo Rococó o Chinesco.

Palabras clave: dorado, marmolado, retablos, Rococó

\section{Imitation of golded marbles in Rococo polychrome altarpieces. A new technique}

Abstract: In the Spanish altarpieces of eighteenth century we find a varied repertory in gilding alternating with matte and shinny effects, chiselled and bronzed. Here we present a technique unknown until now that combines the bronze effect with the imitation of marble.

The first time we found this technique was in Madrid, in Meco's mayor altarpiece; then in Avila, Najera, Coria and Albarracin. In two cases, Meco and Avila, the name of Prospero Mortola, crown guilder, has been documented. It was also located outside of Spain, in the church of Saint Prisca in Taxco, Mexico.

Therefore we find ourselves before a new baroque polychrome technique that we can date between the early and middle thirds of the XVIII Century, which is associated with Rococo or Chinesco style".

Keyword: gilding, marble imitation, altarpieces, Rococo

\section{Dourados marmoreados na policromia de retabulos rococós. Uma nova técnica}

Resumo: Em retábulos Espanhóis do século XVIII encontra-se um variado repertorio de finalizações douradas que alternam entre efeitos mates e brilhantes, cinzelados e efeito de bronze. Apresenta-se aqui uma técnica, até agora desconhecida, que combina o bronzeado com um efeito marmoreado.

A primeira vez que encontrámos esta técnica foi em Madrid, no retábulo Maior de Meco; posteriormente localizámo-la em Ávila, Nájera, Coria e Albarracín. Em dois casos, Meco e Ávila, documentou-se o nome de Próspero Mortola, dourador real. Também se localizaram fora de Espanha, no México, na Igreja de Santa Prisca, em Taxco.

Por tanto, falamos de uma nova técnica de policromia barroca que podemos situar entre finais do primeiro terço e o segundo terço do século XVIII, e que se associa ao estilo Rococó o Chinesco.

Palavras-chave: dourado, marmoreado, retábulos, Rococó 


\section{Introducción}

En las policromías de los retablos del siglo XVIII el oro cobra protagonismo cubriendo arquitecturas y mazonerías desarrollando un variado repertorio de acabados en los dorados a través del juego de efectos mates y brillantes, cincelados y bronceados. Madrid era entonces el centro de referencia y en las regiones periféricas se demandaban los dorados al estilo de lo que se hacía en la Corte, así como el apreciado oro de sus batihojas.

Se presenta aquí una técnica particular de dorado, inédita, que de algún modo se parece a lo que se conoce como bronceado, pero que resulta más compleja. Podría decirse que combina el bronceado con un efecto marmolado.

La primera vez que encontramos estos dorados marmolados fue precisamente durante la restauración del retablo mayor de la iglesia parroquial de $\mathrm{Meco}^{2}$, localidad próxima a Alcalá de Henares, a $37 \mathrm{~km}$ de la ciudad de Madrid.

Posteriormente pudimos localizarla en otros retablos de diferentes poblaciones: Ávila, Nájera (La Rioja) y Coria (Cáceres). En el caso del retablo mayor de la parroquial

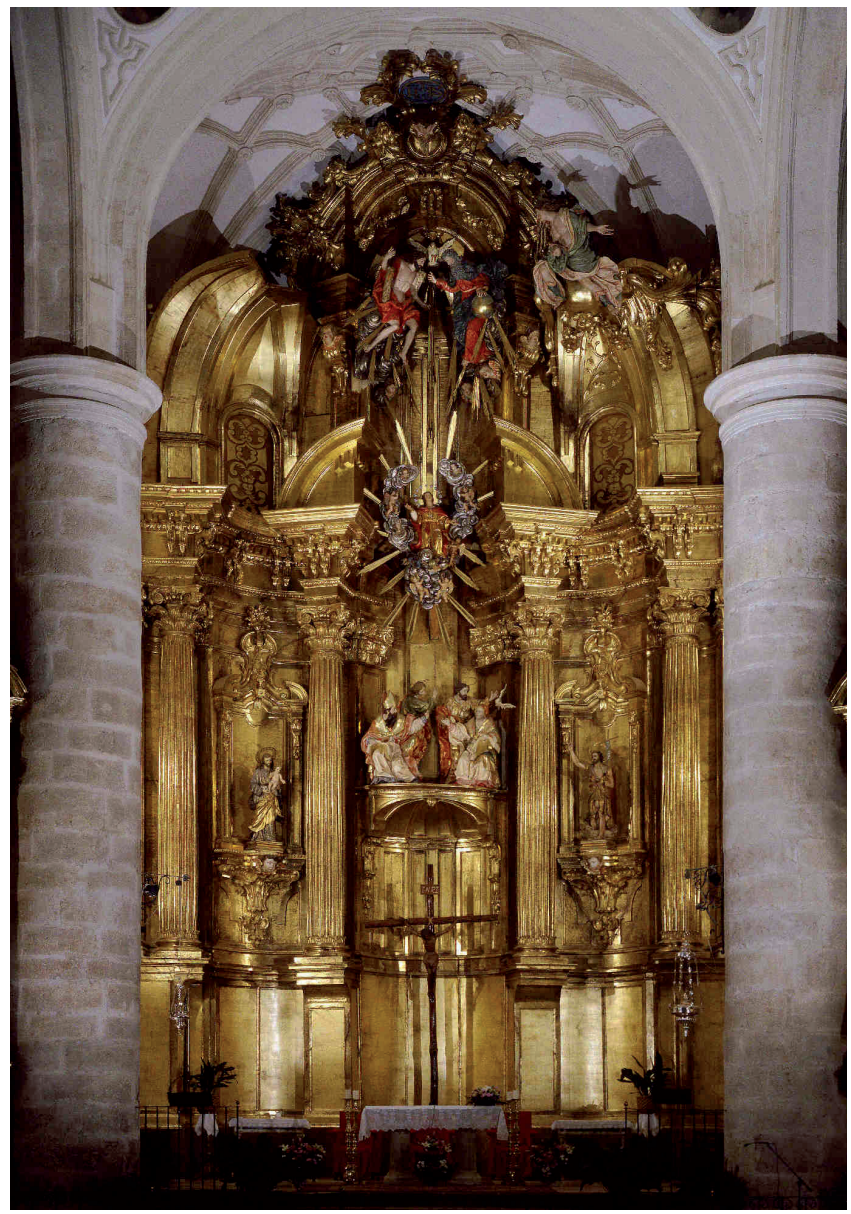

Figura 1.- Retablo mayor de la iglesia parroquial de Meco, Madrid. (Foto Joaquín G. de Llarena) de Meco, realizado en 1744 [figura1] y en el del retablo mayor de la capilla de la Virgen de la Portería, en San Antonio de Ávila, fechado en 1732, se ha podido constatar documental-mente el nombre del dorador y ha resultado ser la misma persona: el artista de origen genovés Próspero Mortola, pintor de escultura y dorador de su majestad.

Fuera de nuestras fronteras se han localizado estos dorados marmolados en México, en los retablos de San Juan Nepomuceno y de la Virgen del Pilar en la iglesia de Santa Prisca, en Taxco, donde es obvia la influencia del español Jerónimo Balbás, quien tras introducir el estípite como soporte en los retablos andaluces decidió viajar y establecerse en la Nueva España implantando allí un estilo que gozó de gran difusión.

Por tanto, nos hallamos ante una técnica de policromía barroca, que podemos situar en los años centrales de la decimoctava centuria, entre 1732 y 1771 y que se asocia, generalmente, con el estilo Rococó o Chinesco.

Suponemos que esta técnica debió aplicarse con frecuencia en la retablística madrileña de la época, así como en otros retablos de las regiones de su área de influencia que, por lo que hemos podido ver hasta ahora, se sitúa en zonas dispersas en el territorio español. Sin embargo es probable que muchos de éstos no hayan llegado hasta hoy por diversos motivos, bien por los daños que sufrieron las iglesias y los conventos de Madrid durante la Guerra Civil de 1936 o bien a causa de las restauraciones de diversa calidad de que han sido objeto los retablos a lo largo de su historia. En este sentido, al ser una técnica de veladuras, combinada con un tratamiento muy peculiar de los panes de oro, cabe suponer que estos acabados en ocasiones pudieran haber sido enmascarados o eliminados, al menos parcialmente, por manos inexpertas y no cualificadas confundiéndose con barnices alterados o con oro deteriorado, pues sólo en las últimas décadas se está poniendo en valor el conocimiento de las técnicas de policromía en paralelo al desarrollo de criterios y metodologías de conservación interdisciplinares y respetuosos con las mismas.

\section{Antecedente del dorado marmolado: bronceados barrocos}

A medida que avanza la retablística barroca hacia nuevas tipologías va cobrando protagonismo el oro hasta terminar cubriendo por completo la mazonería de los retablos, tal como ocurrió en los retablos tardogóticos en los que el oro no dejaba apenas espacio al color. Los doradores desarrollaron su imaginación para crear efectos sobre el dorado y matizarlo o resaltarlo combinando con frecuencia diversas técnicas, tales como el bronceado.

Los "bronceados" se aplicaban localizadamente para diferenciar ciertas zonas de las contiguas. En la mayoría 
de los casos la técnica del bronceado consiste en la aplicación de veladuras sobre el oro -bruñido o no- con ligera carga de pigmento y aglutinadas con medios oleosos o acuosos (aceite, huevo, agua cola o goma). En los condicionados de los documentos contractuales se menciona frecuentemente el bronceado, sin embargo no aportan datos significativos acerca de la técnica o técnicas de su ejecución. En las últimas décadas se han realizado análisis y estudios acerca del bronceado en el retablo barroco español, la mayoría referidos a casos concretos y propiciados por las intervenciones de restauración en retablos madrileños y del País Vasco.

Como antecedente de la técnica que a continuación explicaremos nos referiremos a tres retablos de los siglos XVI, XVII y XVIII:

Retablo mayor de la iglesia de San Mateo en Lucena (Córdoba), obra de Gerónimo Hernández y Juan Bautista Vázquez el Viejo, realizada entre 1573 y 1579. Éste es el testimonio más antiguo de bronceado que se ha encontrado; consta documentalmente que fue policromado en 1607 por Antonio Mohedano de la Gutierra. Presenta dorados bruñidos y veladuras en dos tonos, bronceados y cobrizos, alternados con dorados mates.

Retablo mayor de la iglesia parroquial de Sto. Domingo de Silos en Pinto (Madrid), 1637-1657, obra de los hermanos de la Torre, entre los que hay que destacar a Pedro. Entre los retablos barrocos madrileños de este estilo pudo haber otros ejemplos como éste, que aún conserva bronceados en la decoración vegetal, sin embargo en los que se han restaurado hasta ahora no se han encontrado restos.

Retablo mayor de la iglesia del convento de Las Calatravas (Madrid), 1721-24, obra de José Benito de Churriguera. El dorado alterna el bruñido y el mate, este último realzado con veladuras transparentes de tono rojizo. El juego de contrastes permite obtener composiciones de aspecto pictórico y las veladuras sobre el oro crean efectos bronceados que se generalizan en el siglo XVIII, especialmente en retablos de estilo rococó.

\section{Técnica del dorado marmolado}

Esta técnica consiste en la combinación de diferentes tratamientos en la superficie del dorado al agua sobre madera consiguiendo los efectos producidos por el veteado e irisaciones del mármol y del jaspe. Ésta requiere mucha habilidad por parte del dorador para que el resultado sea natural y artístico. Dichos efectos se obtienen de tres formas que pueden ir alternadas o superpuestas:

1. Veteado. Se obtiene de dos maneras, bien pintando las vetas a punta de pincel sobre el dorado o bien

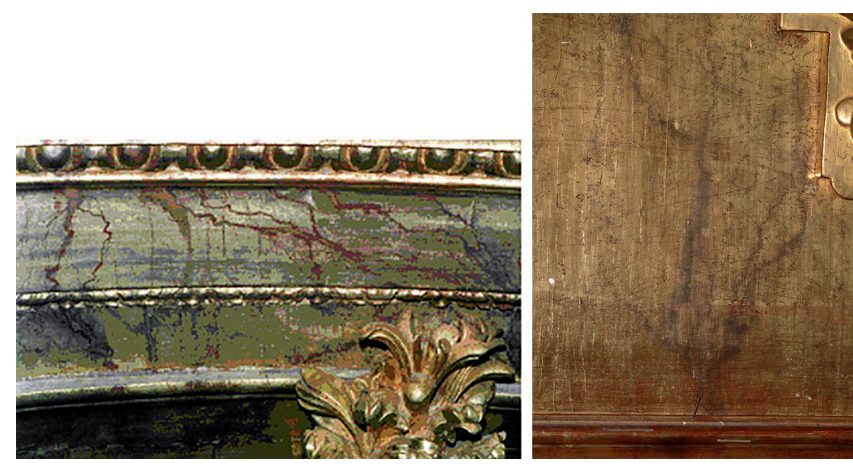

Figura 2.- a-Veteado que deja el bol rojo a la vista. Retablo mayor de Meco. b-Vetas pintadas a punta de pincel. Retablo de la Virgen de Portería, San Antonio de Ávila. (Fotos a- Bárbara Hasbach bJoaquín G. de Llarena).

levantando la lámina dorada con el pincel posiblemente húmedo para crear la forma de las vetas a través del bol rojo subyacente, que queda así a la vista. Posteriormente se bruñe la superficie quedando totalmente lisa. Probablemente esto es lo que llaman "venas" en el contrato de Ávila que veremos más adelante. [figura2]

2. Veladuras y bronceado. Se aplican veladuras transparentes con pigmentos negros, pardos o rojizos que dan como resultado un efecto ahumado sobre el dorado añadiendo vetas o veladuras cobrizas, a modo de bronceado, logrando destellos metálicos. De aquí la denominación de dorados bronceados. [figura3]

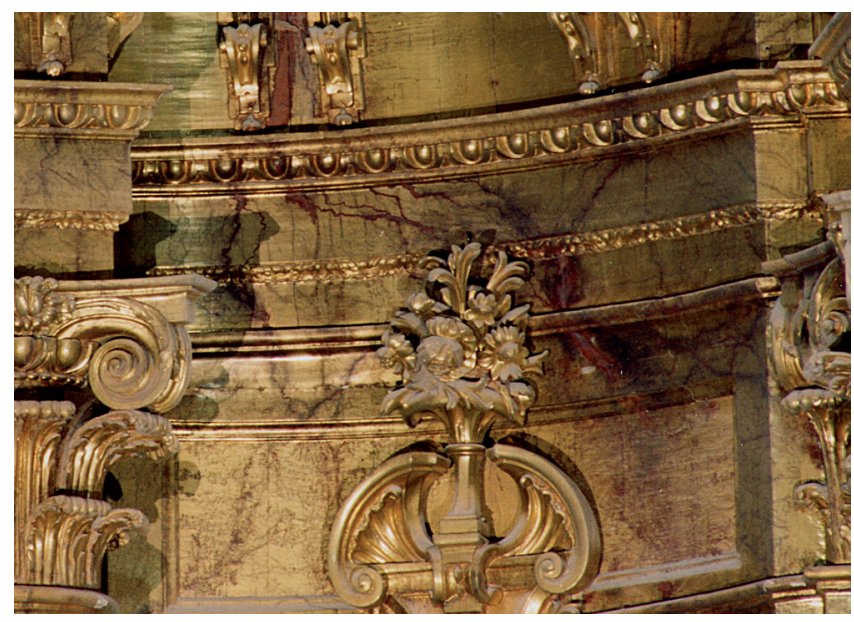

Figura 3.- Veteados con veladuras oscuras creando un efecto ahumado. Retablo mayor de Meco. (Foto Bárbara Hasbach)

3. Dorado roto. Se consigue por medio de la rotura o rasgadura irregular de la hoja de oro produciendo una discontinuidad que deja a la vista el bol, por lo general rojo, asentado sobre una primera capa de color amarillo. Finalmente se bruñe produciendo el efecto de aguas, o de pequeñas irisaciones del mármol. Donde el dorado es mate se aplica una delgada capa como estrato de recubrimiento final posiblemente de cola o a base de huevo [figura4 y figura7d]. 

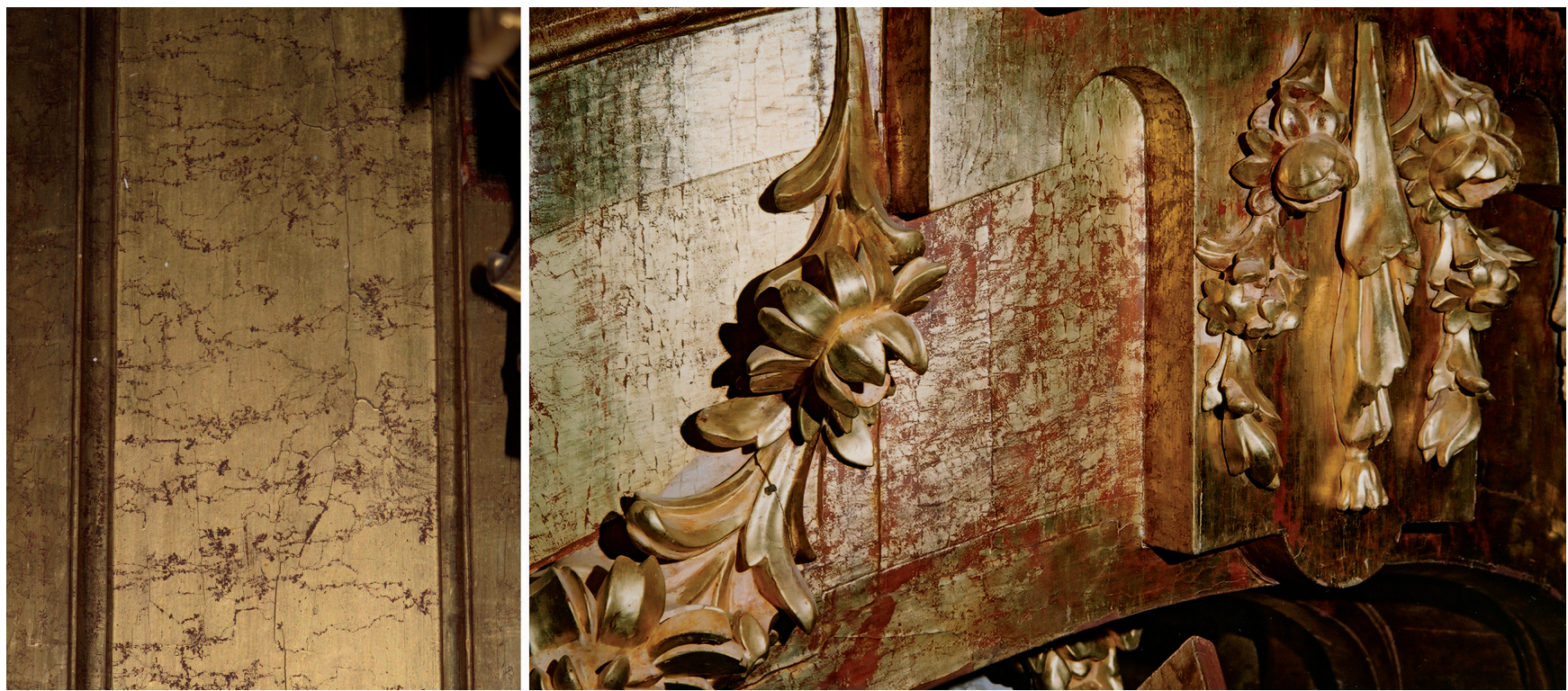

Figura 4.- a- Dorado roto sobre superficie mate. Retablo de la Virgen de Portería, San Antonio de Ávila. b- Dorado roto sobre superficie bruñida. Retablo Mayor de Meco. (Fotos Bárbara Hasbach).

Se ha observado, por medio del análisis microscópico, que donde hay dorado roto hay zonas que no presentan adhesivo (agua cola) del pan de oro, por lo que el mismo no se adhiere de forma regular y puede desprenderse sin esfuerzo. Si se provoca el desprendimiento parcial de la hoja metálica con un pincel o una pelonesa, utilizándolos con mucha destreza, se consigue este efecto marmolado lleno de espontaneidad. Hemos realizado ensayos para reproducir la técnica consiguiendo este resultado por medio de la colocación de las láminas de oro con la pelonesa dejando fallos en el dorado de forma intencionada.

Contamos con los análisis químicos de dos obras, una el retablo mayor de Meco, realizados durante la restauración que llevamos a cabo en 2004 y otra el retablo mayor de Santa María de Nájera, proporcionados por José

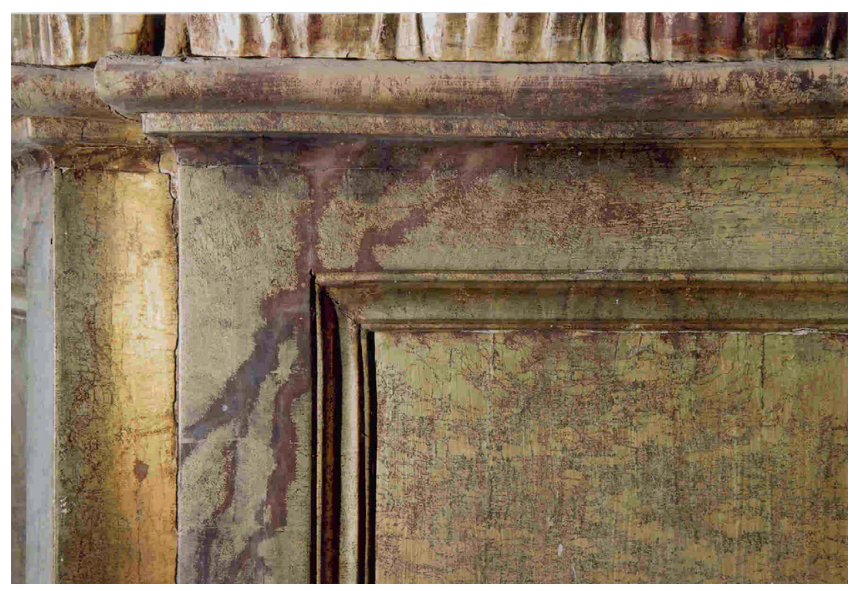

Figura 5.- Detalle que muestra varios tipos de dorado marmolado: veteado dejando a la vista el bol rojo, veladuras ahumadas en la moldura superior y dorado roto en el plano del fondo (zona inferior derecha de la foto). Retablo mayor de Meco, Madrid. (Foto Bárbara Hasbach)
Luis Birigay, restaurador del mismo. En ambos casos se aprecian varias coincidencias: el dorado marmolado se presenta sobre dos estratos de bol, el inferior de color amarillo compuesto de tierra amarilla y yeso y el superior, de color rojo compuesto de tierra roja (estos mismos colores se observan a simple vista en el retablo de Ávila). La lámina de oro es una aleación de oro y pequeñísimas cantidades de plata y cobre, y ambos presentan una capa de recubrimiento similar.

\section{Retablos estudiados con dorado marmolado}

A continuación se relacionan por orden cronológico los siguientes retablos que cuentan con el denominador común de esta técnica.

- 1732-33. ÁVILA. Iglesia de San Antonio. Retablo mayor de la capilla de la Virgen de la Portería.

- 1743-44. MECO (Madrid). Iglesia parroquial de Ntra. Sra. de la Asunción. Retablo mayor.

- 1748. CORIA (Cáceres). Catedral. Retablo mayor.

- 1754-57. TAXCO (México). Iglesia de Santa Prisca. Retablos de San Juan Nepomuceno y de la Virgen del Pilar.

- 1770-1. NÁJERA (La Rioja). Iglesia del Monasterio de Santa María la Real. Retablo mayor y colateral del lado de la Epístola; el colateral del lado del Evangelio presenta esta técnica de forma puntual.

- 1680-81. ALBARRACÍN (Teruel). Catedral. Retablo mayor. Posible repolicromado del dorado del retablo renacentista (1566-82) en el siglo XVIII. 


\section{-Ávila. Retablo mayor de la capilla de la Virgen de la Portería, en la iglesia de San Antonio. 1732}

\section{Dorador. Próspero Mortola, dorador del rey.}

Fecha del dorado: Contratado en Madrid en 1732 por el síndico de la Virgen de la Portería, actuando como fiador el maestro batidor de oro Dionisio Sánchez.

"Yten que ha de hir todo de oro limpio, lo más subido y más hazendrado que se pueda encontrar. Yten que han de ir todas las venas y fondos de talla bronzeados, como asimismo todas las molduras que se corresponden. Más es condición que todo lo que toca a zincelado, bronzeado y estofado ha de ser de mano del otorgante". (Madrid. 20-VI$1732)^{3}$

Características del dorado: Hay dorado roto y tres tipos de vetas: vetas grises largas, vetas negras y vetas pequeñas dejando ver el bol rojo, al tacto es totalmente liso. El marmolado cubre toda la mazonería dorada excepto las columnas y la decoración tallada; los fondos marmolados se encuentran sobre dorado mate. Se aprecian dos capas de bol, primero amarillo y encima rojo, en las zonas donde va dorado, se enriquece el conjunto con labores de cincelado de diferentes motivos.

Características de la policromía de las esculturas: Estofados. Bronceado en los arcángeles con veladuras sobre oro de color cobrizo y verde y encarnaciones mates con aparejo color anaranjado, posiblemente de minio. [figura 6]
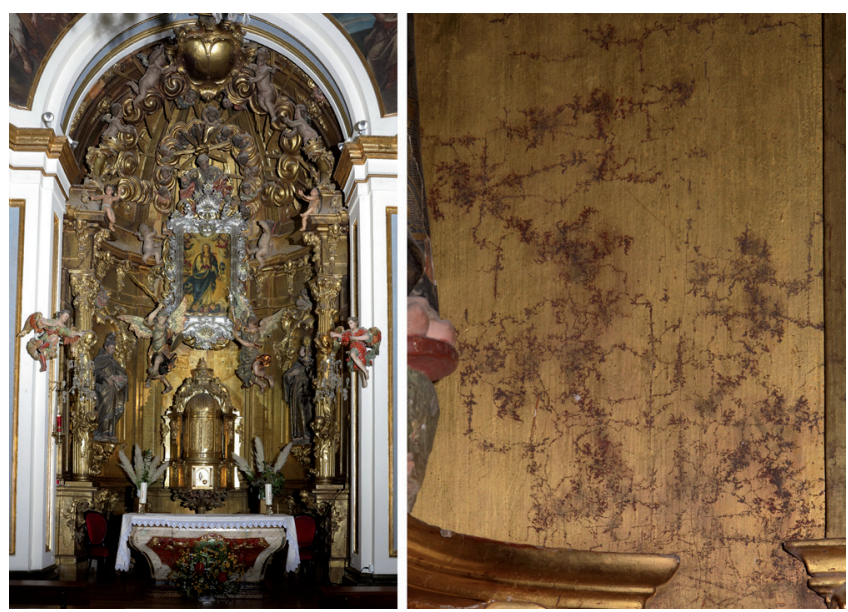

Figura 6.- a- Retablo de la Virgen de la Portería en San Antonio de Ávila. b- Dorado roto sobre superficie mate en los fondos de la arquitectura. (Fotos Joaquín G. de Llarena)

-Meco, Madrid. Retablo mayor de la iglesia parroquial de Nuestra Sra. de la Asunción. 1739-1743

Dorador: Próspero Mortola

Fecha de dorado: 1742 / 1743
Características del dorado: Dorado roto, veteado a punta de pincel, con vetas rojas que dejan ver el bol, veladuras ahumadas y en tonos rojizos. Estas técnicas se alternan sobre superficies de dorado bruñido y mate. El marmolado se localiza en toda la superficie de la arquitectura a excepción de los capiteles de las grandes columnas, el fondo de los cuerpos laterales del ático y la ornamentación vegetal de las hornacinas del primer cuerpo y del coronamiento del retablo, siendo en este caso el dorado bruñido liso.

Características de la policromía de las esculturas: Esgrafiados y decoración a punta de pincel a base de grandes motivos vegetales en contraste con colores planos. Otra variedad de la decoración son rameados a punta de pincel sobre fondos de colores lisos con toques de oro a la sisa. En general están realizados al óleo, aunque también se recurre al temple de cola animal en algunas prendas lisas de las imágenes. Las encarnaciones de aspecto mate son al óleo.

Análisis de laboratorio: En el Laboratorio de Materiales del Departamento Científico de Conservación del Instituto del Patrimonio Cultural de España, se analizaron cinco micromuestras del dorado de la arquitectura del retablo de Meco: dos con efecto marmolado, dos con efecto ahumado y una de dorado liso bruñido para determinar posibles diferencias. Se obtuvieron las siguientes conclusiones:

1.- El aparejo, aplicado en dos manos, es común en todas las muestras, su composición es de yeso, silicatos en baja proporción y cola de origen animal. La capa superior es de molienda más fina.

2.- Solo en una de las muestras encontramos una fina capa de color anaranjado entre el aparejo y el bol, su composición es a base de yeso, tierras ricas en óxido de hierro y cola de origen animal.

3.- El bol es de color rojo y está compuesto por tierras ricas en óxido de hierro y cola de origen animal. El espesor de esta capa es menor (15 $\mu \mathrm{m})$ en la muestra tomada de la zona de dorado sin marmolado que el espesor medio que presentan las muestras que pertenecen a zonas de dorado con marmolado ( $20 \mu \mathrm{m}-25 \mu \mathrm{m})$.

4.- Las láminas metálicas analizadas son pan de oro con pequeñas cantidades de plata 3,52\% y de cobre 1,3\% como promedio. Hay diferencias en su disposición: en las muestras pertenecientes a zonas con marmolado la lámina es discontinua y su fijación sobre el bol es muy débil, pudiendo desprenderse y doblarse con mucha facilidad. Mientras que el pan de oro es una lámina continua en la muestra que corresponde a la zona de dorado sin marmolado. El espesor es similar en ambos casos 1-1,5 $\mu \mathrm{m}$ en el dorado con marmolado y de $1 \mu \mathrm{m}$ en el dorado liso.

5.- Sobre el pan de oro mate se observa una fina capa de protección o recubrimiento de material proteico que podría relacionarse con huevo. 
6.- En las muestras concernientes a zonas con marmolado de veta gruesa y con efecto de ahumado existe una capa de color oscuro, que tendría un efecto pictórico, sobre el estrato orgánico que protege el oro. [figura7] [Tabla 1]

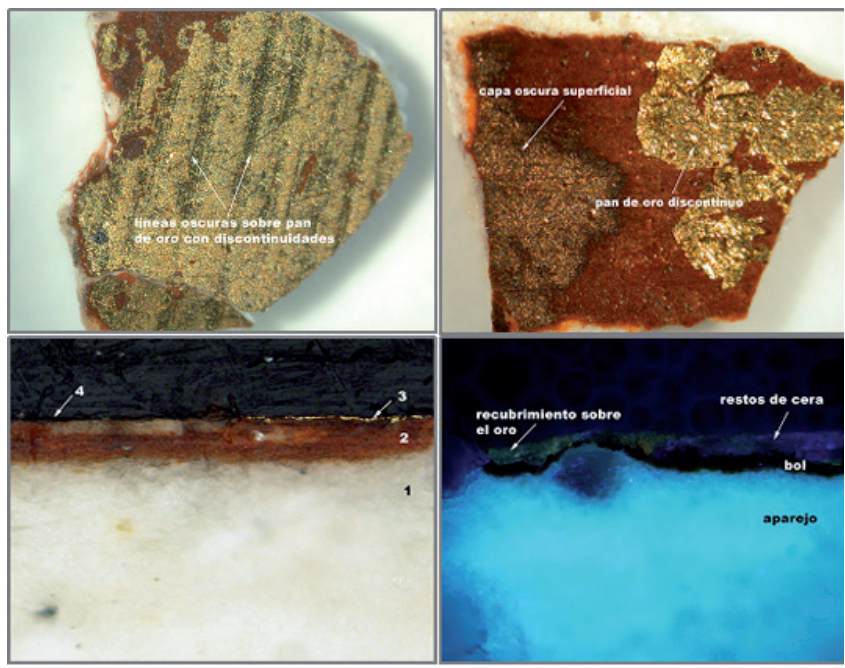

Figura 7.- . Micromuestras del Retablo de Meco. a- Efecto marmolado de veta gruesa. b- Discontinuidad del pan de oro y restos del estrato oscuro de la superficie. c- Estratigrafía: yeso, capa anaranjada, bol rojo y oro. d- Imagen luz UV se aprecian vestigios de un recubrimiento sobre el oro que posiblemente contiene huevo. (Foto Laboratorio IPCE)

Tabla 1.- En esta micromuestra se puede observar la capa de bol aplicada en dos manos, una primera de color amarillo compuesta por tierra amarilla y yeso, y una segunda muy fina de color rojo compuesta por tierra roja.

\begin{tabular}{|l|l|l|l|l|}
\hline Capa & Color & $\begin{array}{c}\text { Espesor } \\
(\mathbf{m})\end{array}$ & $\begin{array}{l}\text { Pigmentos/ } \\
\text { Cargas/Lám. } \\
\text { metálicas }\end{array}$ & Observaciones \\
\hline 5 & pardo & 5 micras & - & recubrimiento \\
\hline 4 & dorado & $1-2$ & $\begin{array}{l}\text { Oro: } 90 \% \text { Pla- } \\
\text { ta: } 7 \% \text { Cobre: } \\
3 \%\end{array}$ & película de oro \\
\hline 3 & rojo & $0-5$ & tierra roja & $\begin{array}{l}\text { bol de asiento } \\
\text { del oro }\end{array}$ \\
\hline 2 & amarillo & 15 & $\begin{array}{l}\text { tierra amarilla, } \\
\text { yeso }\end{array}$ & $\begin{array}{l}\text { bol de asiento } \\
\text { del oro }\end{array}$ \\
\hline 1 & blanco & 550 & yeso & aparejo \\
\hline
\end{tabular}

\section{-Nájera. Retablo mayor de la iglesia del Monasterio de Santa María la Real. 1692-1771}

Pintor-Dorador: José Benito Bravo (de mazonería y relieves).

\section{Fecha del dorado y la policromía: 1770-71}

Características del dorado: Hay dorado roto y dos tipos de vetas, a saber, vetas rojas largas y vetas pequeñas dejando ver el bol rojo. En la mazonería se combina el oro bruñido y el bronceado sobre bol rojo con el oro mate sobre bol amarillo. Enriquecen el juego de luces los destellos metálicos a través de las veladuras color cobrizo, las labores de cincelado realizadas sobre el aparejo y la decoración geométrica incisa.

Características de la policromía de las esculturas: Estofados, veladuras sobre oro y encarnaciones de acabado mate.

Análisis de laboratorio: Arte LabS.L. Micromuestra del dorado de la arquitectura del retablo de Nájera con marmolado donde se obtuvieron los siguientes resultados: [figuras 8 y 9 ]

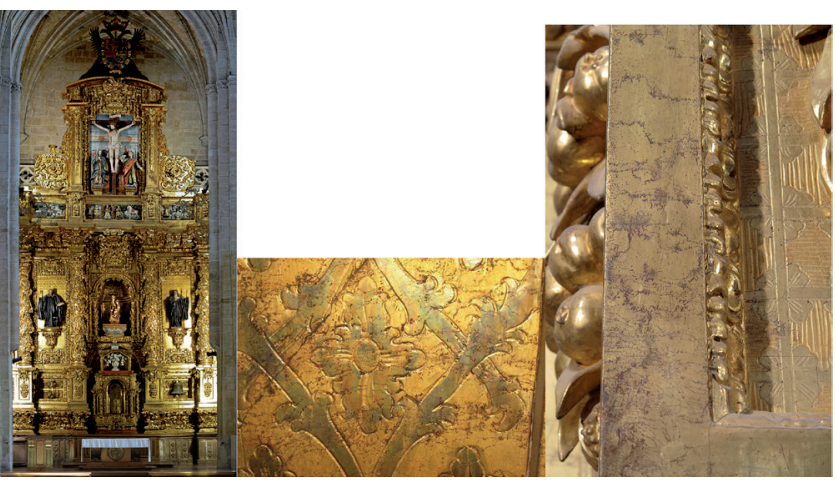

Figura 8.- a- Vista general del retablo. b- Detalle de dorado roto sobre fondo que combina el acabado bruñido y mate. c- Vetas de distintos tipos. (Fotos Joaquín G. de Llarena, central: José Luis Birigay)

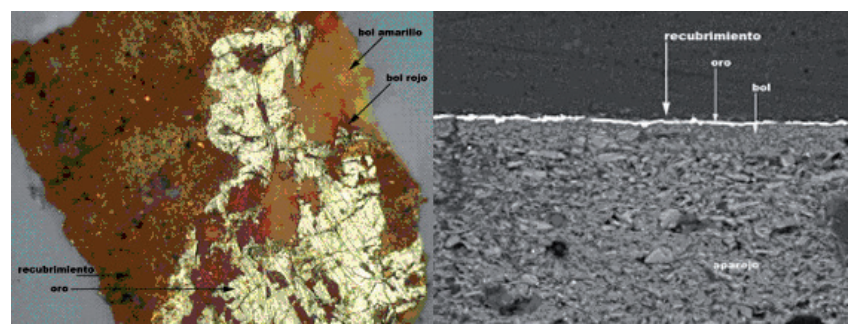

Figura 9.- Micromuestras Retablo de Nájera. Imágenes con microscopio óptico. La capa de oro es de espesor irregular y está dividida en segmentos. (Foto Arte Lab S.L.)

\section{- Coria. Retablo mayor de la Catedral. 1747}

Dorador: Anónimo. La policromía de las esculturas es de Eugenio Pitis, pero no consta nombre del dorador.

Fecha de dorado: 1748 (Inscripción en el dorado)

Características del dorado: Dorado roto, veteado a punta de pincel, veladuras ahumadas y en tonos rojizos. Los tres recursos se localizan alternados sobre las superficies de dorado bruñido y mate.

Características de la policromía de las esculturas: Alternan los estofados y esgrafiados que componen grandes motivos 
vegetales con los colores planos. Las encarnaciones son semi mates.

\section{— Taxco, México. Iglesia parroquial de Santa Prisca}

Los retablos se realizaron en los años en los que Isidoro Vicente Balbás estuvo trabajando en Taxco, entre 1752 y 1757.

Aquí se mencionan sólo dos retablos de este templo, pero es posible que se aplicase este tipo de decoración en algunos más como ocurre en los de San José y el de la Virgen de Guadalupe ambos con tímidas vetas, que deberían ser comprobadas en un examen pormenorizado.

\section{- 1.-Retablo de la Virgen del Pilar y los 7 Arcángeles.}

Dorador: Silvestre Reynoso

\section{Fecha del dorado: 1754-57}

Características del dorado: Dorado roto y tres tipos de vetas, pintadas sobre el dorado con pigmentos rojo y negro, vetas rojas largas y anchas y vetas pequeñas dejando ver el bol rojo. Se encuentran en toda la superficie de la arquitectura dorada.

Características de la policromía de las esculturas: Esgrafiados y grandes motivos vegetales a punta de pincel sobre el dorado, cincelados y encarnaciones pulidas. [figura 10]

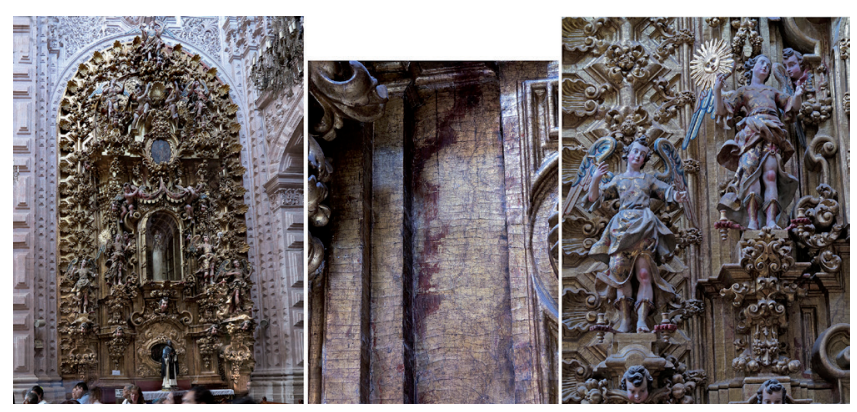

Figura 10.- Retablo Virgen del Pilar y los siete arcángeles, Iglesia de Santa Prisca, Taxco y distintos tipos de vetas y dorado roto. (Fotos Joaquín G. de Llarena)

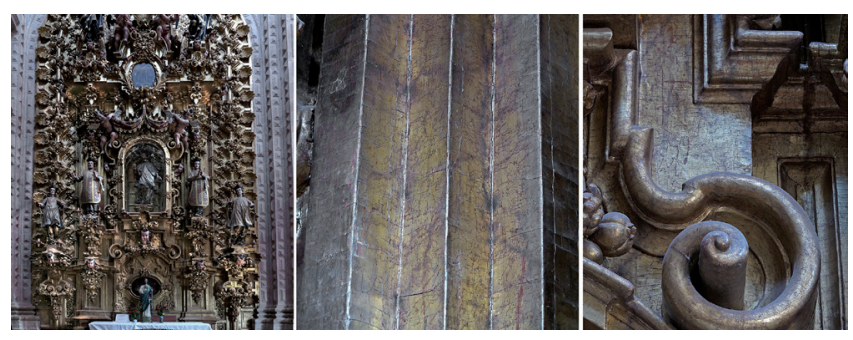

Figura 11.- Retablo de San Juan Nepomuceno, Iglesia de Santa Prisca, Taxco. Vista general del retablo y distintos tipos de vetas y dorado roto en casi toda la superficie del mismo. (Fotos Joaquín G. de Llarena)

\section{- 2.-Retablo de San Juan Nepomuceno}

Dorador: Silvestre Reynoso

Fecha del dorado: 1754-57

Características del dorado: Dorado roto y tres tipos de vetas: pintadas sobre el dorado con pigmentos rojo y negro, vetas rojas largas y anchas y vetas cortas dejando ver el bol rojo. Se encuentran en toda la superficie de la mazonería dorada.

Características de la policromía de las esculturas: Cincelados, estofados esgrafiados y grandes motivos vegetales a punta de pincel sobre el dorado. Encarnaciones a pulimento. [figura 11]

\section{- Albarracin. Retablo mayor de la Catedral. 1566-1582}

Dorador: Rillo

Fecha del dorado: 1680-81.

Características del dorado: Dorado roto y dos tipos de vetas, rojas largas y vetas cortas dejando ver el bol rojo. Seencuentran en toda la superficie de la arquitectura dorada sin relieve.

Características de la policromía de las esculturas: Estofados y encarnaciones semi mates.

Nuestra hipótesis es que el marmolado se realizase cuando se doró el retablo a finales del siglo XVII o que corresponda a una repolicromía del siglo XVIII en el contexto de las numerosas obras que se ejecutaron en la catedral en este tiempo. Si la primera hipótesis fuera cierta nos encontraríamos ante la primera referencia de marmolado conocido. [figura 12]

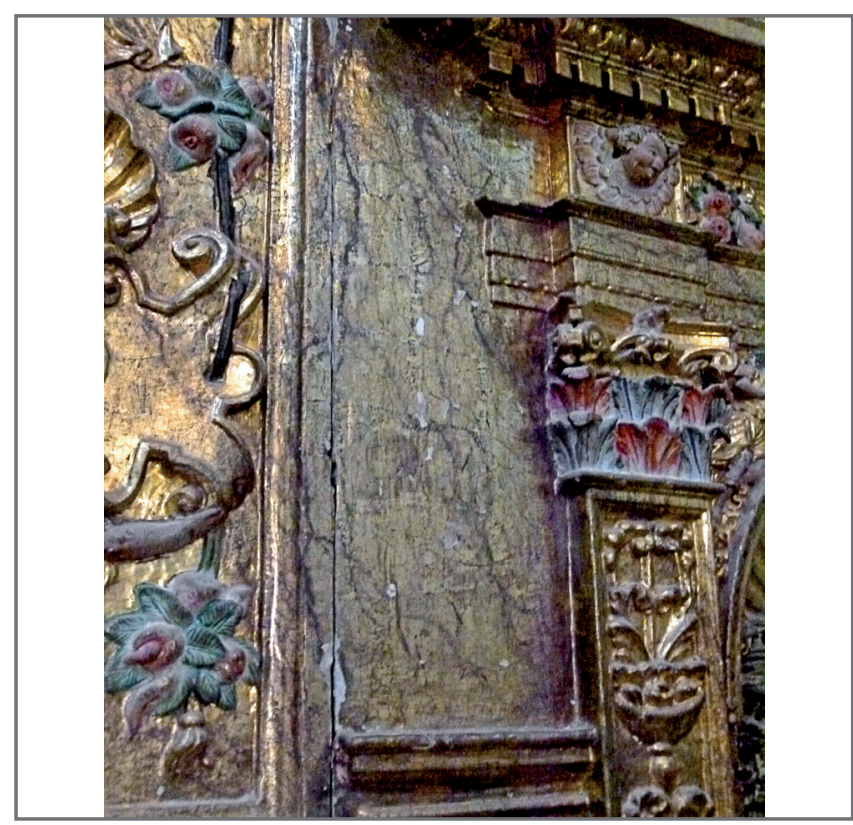

Figura 12.- Detalle de la repolicromía con veteado sobre el dorado en el retablo mayor renacentista de la Catedral de Albarracín, Teruel. (Foto Leticia Pérez de Camino) 


\section{Conclusiones}

Desde que se localizó por primera vez esta técnica en el año 2004, durante la restauración del retablo de Meco, financiada por la Comunidad de Madrid, estamos desarrollando un proyecto que pretende localizar nuevos ejemplos, con el fin de obtener un registro de los mismos. Esto redundará en un mejor conocimiento de los dorados marmolados, así como en su difusión, ambas cosas necesarias para favorecer su protección.

Aprovechamos esta ocasión para invitar a aquellos profesionales que hayan podido reconocer esta técnica a contactar con las autoras a través de las direcciones electrónicas indicadas en este artículo. El objetivo es realizar un mapa de localizaciones en las regiones españolas, mexicanas o de cualquier otro lugar donde pudieran encontrarse.

\section{Agradecimientos}

Joaquín Gómez de Llarena (fotografías de los retablos de Meco, Ávila, Taxco y Nájera)

José Luis Birigay (datos documentales, análisis y fotografías del retablo mayor en Nájera)

Rocío Bruquetas, Ana Carrassón y Leticia Pérez de Camino (noticias y fotografías del retablo de Albarracín)

\section{Notas}

[1] Este trabajo, aún inédito, fue presentado como ponencia en ENCRUCIJADA, III Congreso Internacional sobre Escultura Virreinal, Cádiz, 2012.

[2] Restauración realizada por Ágora. Restauraciones de arte S.L. para la Dirección General de Patrimonio Histórico de la Consejería de Cultura de la Comunidad de Madrid.

[3] VERDÚ, M., 1987, 19-21.

\section{Bibliografía}

CARRASSÓN LÓPEZ DE LETONA, A., GÓMEZ ESPINOSA, T., GÓMEZ GONZÁLEZ, M. (2003). "Restauración del retablo mayor de la iglesia de San Mateo de Lucena", Bienes Culturales, 2: $149-164$.

CARRASSÓN LÓPEZ DE LETONA, A., GÓMEZ ESPINOSA, T., GÓMEZ GONZÁLEZ, M. et. al. (2004) "Las técnicas del dorado". En Actas del Congreso Internacional A Escultura policromada religiosa dos séculos XVII e XVIII. Estudo comparativo das técnicas, alteraçoes e conservaçao em Portugal, Espanha e Bélgica. Instituto Portugués de Conservaçao e Restauraçao, Lisboa 2002, 189-196.
GARCÍA GUTIÉRREZ, F.J. (2002). Historia de Meco, 2ª ed., Meco, Ilmo. Ayuntamiento de Meco, Madrid.

GÓMEZ ESPINOSA, T., REBOCHO-CHRISTO, J.A., MOURA, C. et. al. (2004) "História e Evoluçao da Policromia Barroca". En Actas del Congreso Internacional: A Escultura policromada religiosa dos séculos XVII e XVIII. Estudo comparativo das técnicas, alteraçoes e conservaçao em Portugal, Espanha e Bélgica. Instituto Portugués de Conservaçao e Restauraçao, Lisboa 2002, 37-54.

VARGAS LUGO, E. (1999). La iglesia de Santa Prisca de Taxco, U.N.A.M., México.

VERDÚ, M. (1987) “La advocación de Nuestra Señora de la Portería y de la capilla construida en su honor dentro del convento abulense de San Antonio", Cuadernos Abulenses, Institución Gran Duque de Alba. Excma. Diputación Provincial de Ávila, 8: 11-92. 


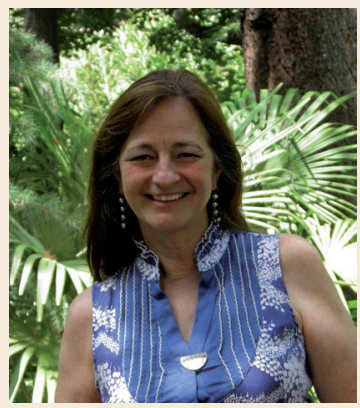

\section{Bárbara Hasbach Lugo}

bjagora1@telefonica.net

Ágora. Conservación y Restauración de Arte, S.L.

Licenciada en restauración de bienes muebles en la Escuela Nacional de Restauración de México, con especialidad en restauración de escultura de madera policromada por el Instituto Central de Restauración de Madrid.

En su amplia labor destacan sus estancias en Granada con la restauración de esculturas de gran relevancia, así como la dirección de la conservación y restauración de las exposiciones "Pedro de Mena y su época”, en la Catedral de Málaga o de las esculturas de la exposición "Arte Sacro de la Diócesis de Madrid-Alcalá" en el Palacio de las Alhajas de Madrid. En 1989, junto con Juan Aguilar Gutiérrez, crea en Madrid la empresa Ágora Restauraciones de arte, S.L. Desde entonces han restaurado, con su equipo, importantes conjuntos artísticos, principalmente en Andalucía y Madrid destacando el Peinador de la Reina en la Alhambra; la capilla mayor y parte de la cúpula de la basílica de San Francisco el Grande de Madrid; la reja mayor y sala capitular del Monasterio de Guadalupe; las pinturas murales de la iglesia de Villa del Prado, Madrid; los mausoleos de los Reyes Católicos de la Capilla Real de la Catedral de Granada o la bóveda pintada por Luca Giordano en el Casón del Buen Retiro perteneciente al Museo del Prado. Cuenta con diversas publicaciones conjuntas sobre las obras restauradas

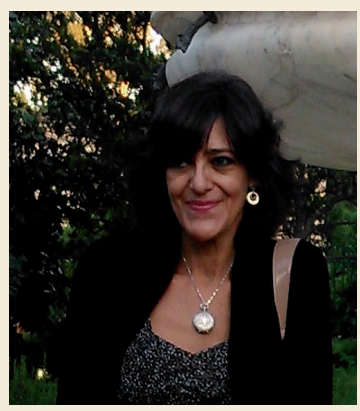

Teresa Gómez Espinosa

teresag.espinosa@mecd.es

Museo Arqueológico Nacional

Licenciada en Geografía e Historia. Especialidad en Historia del Arte, por la Universidad de Salamanca, y en Prehistoria y Arqueología, por la Universidad Autónoma de Madrid. En 1995 ingresa en el Cuerpo Facultativo de Conservadores de Museos. Ha trabajado desde 1981 hasta 2009 en el Instituto de Patrimonio Cultural de España, del Ministerio de Educación Cultura y Deporte, donde ha dirigido la Sección de Conservación y Restauración de Obras de Arte y, después, el Servicio de Información. Desde 2009 hasta finales del 2011 ha trabajado en el Museo de América, como conservadora responsable del Departamento de Conservación y Restauración. Desde 2011 hasta la actualidad es la conservadora jefe del Departamento Técnico de Conservación del Museo Arqueológico Nacional.

Ha realizado numerosos trabajos tanto en España como en América Latina y ha participado en diferentes proyectos internacionales de investigación. Trabajos que han sido difundidos en diferentes foros profesionales, en cursos, en conferencias y en alrededor de cincuenta publicaciones.

Artículo enviado el 26/11/2017

Artículo aceptado el 12/12/2017 